\title{
Bill brought to make botox illegal for under-18s
}

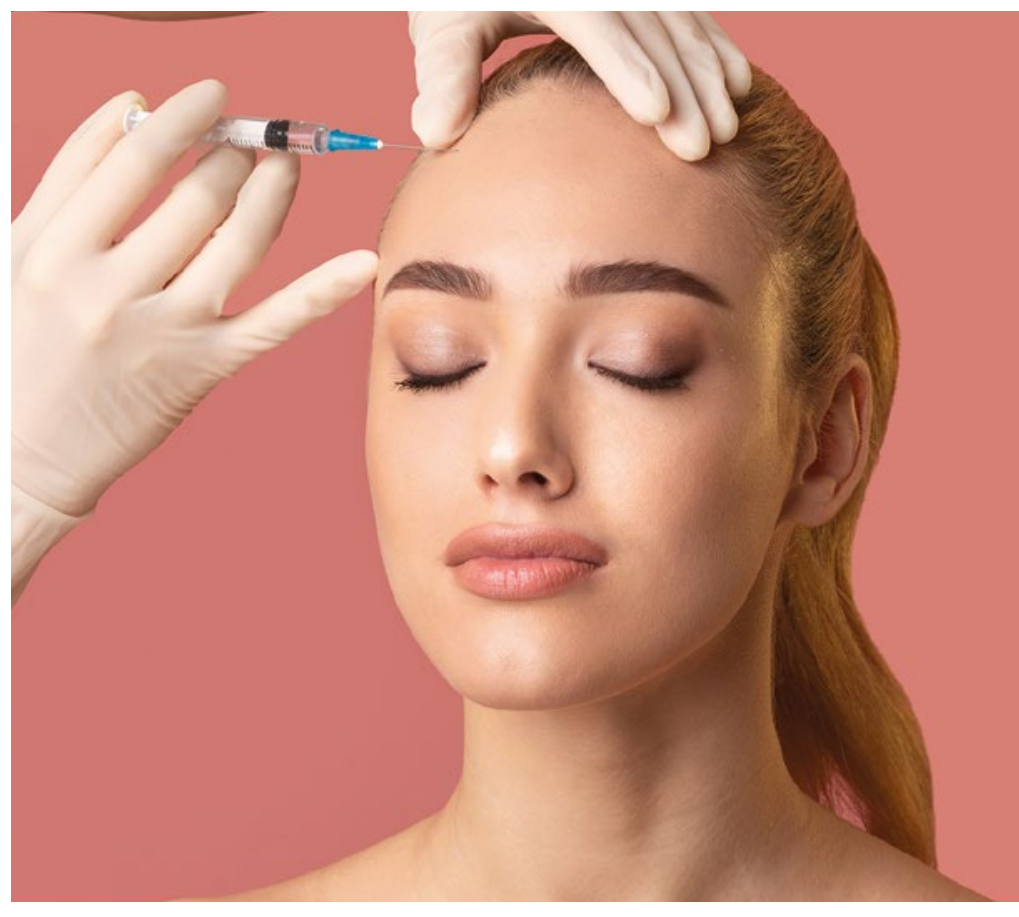

The British Association of Oral and Maxillofacial Surgeons (BAOMS) has welcomed the private members' bill that would make it illegal to give botox or dermal fillers to anyone under 18 for cosmetic purposes. The Botulinum Toxin and Cosmetic Fillers (Children) Bill 2019-21 brought by Laura Trott MP as a private members' bill had its second reading in the House of Commons in October.

Caroline Mills, BAOMS Lead on Facial Aesthetic/Cosmetic Surgery and Consultant Maxillofacial Surgeon at Great Ormond Street Hospital, said: 'BAOMS is pleased that Health Minister Edward Argar has given his backing to this bill, and for his department's commitment to explore increased oversight of aesthetic practitioners. We want this to be the first step towards wider regulation across the industry to protect anyone in the UK undertaking non-surgical cosmetic procedures.

'It is essential that everyone fully understands the risks they are taking when they consider a cosmetic procedure such as a dermal filler or botox, and consult a fully trained medical practitioner. This is why we have consistently called for regulation in the UK to protect patients properly'

Possible complications from botox or dermal filler injections are significant and can cause blindness, severe allergic reactions, chronic ongoing infection and deformity.

BAOMS has for some while voiced concerns about the scope of training, health and hygiene and infection control in the high street beauty salon industry. There is also an increasing cost impact to the NHS to treat high street non-surgical procedures that have complications, and at this time the full scale of the long-term problems remains unknown due to lack of suitable coding within the system. 